July 29, 2019

\title{
The Effects of Paternity Leave on Parents' Earnings Trajectories and Earnings Inequality
}

\author{
Youjin Choi \\ Anders Holm \\ Rachel Margolis
}

\begin{abstract}
Paid parental leave from work reserved for mothers and fathers is one policy that has been proposed to equalize labor force participation, wages, and childcare for men and women. We examine the effects of fathers' use of parental leave on paternal, maternal and family earnings, as well as earnings inequality within the family exploiting the institution of the Quebec Parental Insurance Program which reserved 5 weeks of leave for fathers. We find that ten years after the birth, father's use of parental leave increases family income and makes wages more equal within the family.
\end{abstract}

Keywords: Policy, parental leave, parental benefits, gender wage gap, earnings inequality

\section{Corresponding Author:}

Youjin Choi, Postdoctoral Fellow, University of Western Ontario, ychoi254@uwo.ca

\section{Other Authors:}

Anders Holm, Professor, Department of Sociology and Department of Economics, University of Western Ontario, aholm@uwo.ca

Rachel Margolis, Associate Professor, Department of Sociology, University of Western Ontario, rachel.margolis@uwo.ca

\section{Acknowledgements:}

We acknowledge research funding from the Social Sciences and Humanities Research Council of Canada, Insight Development Grant \#430-2017-00357. We thank Lance Lochner, Nirav Mehta, and participants of the 53rd Canadian Economics Association Meetings and the Social Analysis and Modelling Division brain hour for their helpful comments. 


\section{Introduction}

Over the last century, gender differences in educational attainment, occupations and work hours have decreased dramatically, leading gender gaps in labor force participation and wages to narrow. However, the closing of the gender wage gap has stalled since the 1990s, leaving a significant gap remaining (Goldin 2014; England 2010). In trying to understand the causes of the gender wage gap, researchers have studied the sorting into different fields of study and occupations, different wages for the same work, and changes in work hours and time out of the labor force around parenthood. Recent studies find that the remaining gender wage gap in developed countries are largely accounted for by parenthood (Bertrand, Goldin and Katz 2010; Angelov, Johansson and Lindahl 2016; Kleven, Landais, and Søgaard 2018).

One way that policymakers have tried to decrease the effects of parenthood on the gender gap in labor force participation and wages is to offer paid parental benefits to new parents. These policies are designed to increase the labor supply of parents, and in particular, mothers. Sometimes these benefits are only offered to the mother as maternity leave, but often there are additional weeks for parents to share. Generally, mothers take almost all of this shareable time (Ray et al. 2009). Sometimes, there are weeks of benefits reserved for fathers that are aimed to increase gender equality in care work for children as well as in the paid labor force. Norway first introduced paternity leave reserved for fathers in 1993. It was followed by Sweden, Iceland, Germany, Denmark, and Canada (the province of Quebec in 2006 and the rest of Canada in 2019). After the introduction of paternity leave, these countries experienced a substantial rise in fathers' use of these benefits. Some recent studies have examined how these policies or the use of paternity leave affects fathers' and mothers' earnings in Nordic countries (Johansson 2010; Kotsadam, Ugreninov and Finseraas 2011; Ekberg, Eriksson and Friebel 2013; Rege and Solli 2013; Dahl, Loken and Mogstad 2014; Cools, Fiva and Kirkeboen 2015; Avdic and Karimi 2018; Andersen 2018). However, this empirical literature has found little consensus. Studies find from positive, negative, and null results, sometimes even for the same country. In addition, research on the effects of paternity leave on earnings is entirely on Nordic countries with the exception of Farré and González, which is for Spain (2019).

In this paper, we analyze whether fathers' use of parental leave has an impact on the earnings of fathers, their partners and their family income. The province of Quebec introduced 5- 
week paternity leave as a part of its new Quebec Parental Insurance Plan (QPIP) in 2006. ${ }^{1}$ After the policy reform, there has been a substantial rise in fathers' use of paternity leave in Quebec. We estimate the impact of fathers' use of paternity leave resulting from the QPIP reform on parental earnings by using an instrumental variable (IV) approach with an individual fixed effect. Our analysis uses the longitudinal Canadian tax data in which census family members are linked and the use of parental benefits can be identified. These data allow us to answer how a father's use of parental benefits affects not only their own earnings but also earnings of their partner and family. We analyze how these effects evolve up to 10 years after birth of the first child. Then, we examine whether there are heterogeneous effects across subgroups.

This paper has several important contributions to the literature on paternity leave and parental earnings. First, this paper provides the first evidence that father's use of paternity leave has long-term positive effects on overall family income seven to ten years after a first birth. We argue that family income over this time period is the most relevant time frame and outcome for new parents to be thinking about as they transition to parenthood and decide how to share care and market work within their families. Second, our paper provides the most comprehensive analysis of earnings dynamics within a couple over the long-run surrounding the transition to parenthood. By examining how the effects of use of paternity leave play out differently for men's own earnings and those of their partners, we are able to show how parents' relative earnings within a couple evolves over time and how the policy reform increases gender equality within the couple. Third, we examine how the impacts of using paternity leave affect earnings dynamics over time differently for subgroups where couples are likely to have different labour supply or fertility behavior. Our analysis is stratified by family income quartiles, relative income within the couple and family size. Fourth, our paper provides important new evidence outside the Nordic countries. ${ }^{2}$ All but one paper study the Nordic countries because these countries are the leaders in policies promoting gender equality and have the most advanced administrative data to study the effects of these policies. Canada is a more relevant comparison for many contexts because the Nordic countries are so much more generous than others regarding the length of parental leave and the level of income replacement. To date, our study is the most comprehensive study on the

\footnotetext{
${ }^{1}$ The rest of Canada now has access to paternity leave for births as of March 17, 2019.

${ }^{2}$ Patnaik (2019) shows impact of paternity leave on parental labour supply in the Canadian context, but she did not study impact on future earnings.
} 
topic of paternity leave and parental earnings taking into consideration the breadth of outcomes including household income dynamics, time frame of analysis, and clarity of methods.

We find that there are small negative effects of father's use of leave on his own earnings and large positive effects on his partner's earnings. Five years after their first child is born, the fathers who used paternity leave earn $4.3 \%$ less than those who do not use whereas the mothers whose partner used paternity leave earn $17.8 \%$ more than the mothers whose partner did not. The two effects cancel out each other, and we find no evidence that families suffer from lower family income five years after birth. In fact, we find that ten years after the birth, there is a strong positive effect of father's use of parental leave on family income, and wages are more equal within the family. These findings highlight that a policy designed to shift care and work responsibilities within couples did in fact lead to more equal wages within couples without decreasing overall family income over a 10-year period.

The paper proceeds as follows. Section 2 provides a review of related literature. In Section 3, we provide background on the parental leave programs in Canada and discuss the expected effects of the Quebec reform on parents' future earnings. We then discuss methodology and data for our empirical analysis in Section 4. We present the estimated effects of fathers' use of paternity leave on parents' earnings trajectories, including subgroup analysis, in Section 5. We discuss our findings and conclude in Section 6.

\section{Prior Literature on Paternity Leave and Parental Earnings}

A number of recent studies have empirically examined how paternity leave policies affect parental earnings. Most of the papers examine the Nordic countries, such as Norway (Kotsadam et al. 2011; Rege and Solli 2013; Dahl et al. 2014; Cools et al. 2015), Sweden (Johansson 2010; Ekberg et al. 2013; Avdic and Karimi 2018) and Demark (Andersen 2018), with one paper from Spain (Farré and González 2019). Some of them focus on earnings as the main outcomes (Johansson 2010; Kotsadam et al. 2011; Rege and Solli 2013; Ekberg et al. 2013; Cools et al. 2015; Andersen 2018), but others analyze earnings as supplementary to their main interest which is peer effects in use of leave (Dahl et al. 2014), marital dissolution (Avdic and Karimi 2018), and subsequent fertility (Farré and González 2019). 
Existing research examine the effects of paternity leave on several different outcomes and various time frames. For example, Rege and Solli (2013) examined only fathers' earnings as an outcome, but other papers have examined both fathers' earnings and their spouse's earnings (Johansson 2010; Kotsadam et al. 2011; Ekberg et al. 2013; Dahl et al. 2014; Cools et al. 2015; Avdic and Karimi 2018; Andersen 2018; Farré and González 2019). Of these, the only one that explicitly examines total family income as an outcome is Avdic and Karimi (2018), although others (Dahl et al. 2014; Cools et al. 2015; Andersen 2018) have presented the impact on father's and mother's earnings levels as parallel outcomes but not shown statistical tests for earnings at the family level. For relative earnings within a couple, Avdic and Karimi (2018) and Dahl et al. (2014) examined mothers' income share of total family income, and Andersen (2018) examined the absolute gender wage gap within the household. There is a lot of variation in the time frame analyzed for these studies using various outcomes. For example, studies examine logged monthly wages 1 to 12 years after a policy reform (Ekberg et al. 2013), average earnings two to five years after a focal birth (Cools et al. 2015), total earnings during the first three years after birth (Avdic and Karimi 2018), total earnings during the 12 years after a focal birth (Dahl et al. 2014), and earnings differences between one year before and four years after a focal birth (Andersen 2018). No existing study includes a comprehensive range of outcomes and time frame.

These studies find mixed results about the effects of paternity leave on father's earnings, with some showing negative effects and others no effects, and the results are often mixed even for the same country. It's important to note that all the evidence showing negative effects for fathers' earnings is estimated for the short-term. For example, among Swedish studies, Johansson (2010) and Avdic and Karimi (2018) find that paternity leave policies decrease fathers' future earnings during the first four years after birth, but Ekberg et al. (2013) find no effects on father's long-term earnings. Among Norwegian studies, Rege and Solli (2013) find that the introduction of paternity leave in 1993 had a negative impact on fathers' earnings during the first five years after the focal birth. Meanwhile, Cools et al. (2015) studied the same policy reform and find no effect on fathers' average earnings two to five years after the focal birth, and Dahl et al. (2014) find no impact on total earnings during the first 12 years after the focal birth. The differences between the results of Rege and Solli (2013) and Cools et al. (2015) are likely due to different methodologies in the two papers. The results for Dahl et al. (2014) may not be generalizable due to their more limited analytic sample constructed because of their specific 
focus on peer effects. Outside the Nordic countries, Farré and González (2019) find that the introduction of two-week paternity leave in Spain had no impact on fathers' earnings 6 to 24 months after birth. To our knowledge, there are no studies that show how the impact of paternity leave on earnings evolved over time.

There is mixed evidence on the effects of paternity leave on mothers' earnings. One paper finds a negative short-term impact (Avdic and Karimi 2018). They find that introducing paternity leave in Sweden lowered mothers' labor income during the three years after a birth. They suggest that the policy reform, which held the total length of leave per family constant but increased the share reserved for men, led to mothers taking more unpaid leave rather than returning to work earlier. Three other papers find that paternity leave had positive effects on mother's earnings over the short term. Johansson (2010) finds a positive impact four years after a birth using a fixed effect model, but no impact with a differences-in-differences model. Andersen (2018) finds that father's use of a higher share of total leave positively impacted mother's earnings two to four years after a birth, and Farré and González (2019) find that the introduction of a two-week paternity leave in Spain increased maternal earnings 24 months after a birth. Three other papers have examined the effects of paternity leave on mothers' earnings in the long run and find no effects (Kotsadam et al. 2011; Ekberg et al. 2013; Dahl et al. 2014). To our knowledge, there are no studies showing how the impact changes over time and providing evidence for long-term positive effect on mothers' earnings.

As new parents jointly make a decision about father's use of paternity leave, understanding its impact on family income is important. In particular, there is no clear theoretical prediction on the direction or magnitude of the effect of the father taking leave for family income since this will depend on the relative wages of the couple and the effects of his use of leave on his earnings and his partner's earnings over time. However, despite its importance, there is little analysis that has focused on total family income. The only available paper to examine this is Avdic and Karimi (2018), who find that introducing paternity in Sweden leave lowered total family income during the first three years after birth. Also, the ways in which relative wages within the household are affected is also unclear in the literature. Dahl et al. (2014) find no significant impact on mother's total earnings relative to father's total earnings during the first 12 years after birth. However, Andersen (2018) find that the paternity leave reduces withinhousehold gender wage gaps 2 to 4 years after birth. The lack of evidence for family income 
measure is likely due to overall mixed results about impacts for fathers' earnings and mothers' earnings.

All of the studies we discussed have examined a policy reform as exogenous variation to identify causal effects of paternity leave on earnings. The most commonly used empirical strategies in this literature are Differences-in-Differences (DD) (Rege and Solli 2013; Cools et al. 2015; Avdic and Karimi 2018) and Regression Discontinuity Design (RDD) (Kotsadam et al. 2011; Dahl et al. 2014; Ekberg et al. 2013; Farré and González 2019). Taking a different approach, Johansson (2010), estimated fixed effect models and compared these results to DD models. However, she did not combine the fixed effects analysis with the analysis of the policy reform as an instrument.

\section{Background}

\subsection{The Quebec Parental Insurance Plan (QPIP)}

Canada is an important context for those interested in paid parental benefits policies, especially in North America because the current federal policy offers similar benefits in terms of length of paid time off that is comparable to many European countries, but the level of earnings replacement is at the low end of what is generally offered in Europe. On both dimensions, the Canadian policy is much more generous than the United States. Canada's paid maternity benefits policy was instituted in 1971. At first, the policy offered job-protected maternity leave for women; eligible female workers became entitled to $55 \%$ of their average earnings up to a maximum of $\$ 413$ per week for 15 weeks around the birth of a child. In 1990 and then 2001, the policy was extended, adding weeks of parental leave for parents to split (up to 10 weeks in 1990 and 35 weeks in 2001) (Marshall 1999; HRSDC 2005). As of 2001, the federal policy offered 50 weeks of paid time off work for a birth, with 15 weeks of maternity benefits and 25 weeks for parents to split, all paid at a rate of 55\% of earnings up to $\$ 413 /$ week (HRSDC 2005).

As of January 1, 2006, Quebec instituted its own Parental Insurance Plan (QPIP) which replaced the federal Employment Insurance Parental Benefits Program (PBP) for administering paid benefits to new birth or adoptive parents in Quebec. The parental benefits plan described above remained in effect in all other provinces. The 2006 policy change in Quebec had two main aims. First, it aimed to increase fathers' use of benefits. Second, its longer-term aim was to break down gender stereotypes and promote gender equality by changing the expectation that women 
in the labor force would be doing more parenting than men. Quebec's 2006 policy made five important changes. First, it increased benefit rates from 55\% of average earnings to a max of $\$ 413$ per week to $70 \%$ of average earnings to a maximum of $\$ 767$ per week (Marshall 2008). Second, it instituted a new five-week non-transferable leave for fathers. Third, it increased eligibility for parental benefits by including self-employed people and removing the work hours requirement and replacing it with requiring at least $\$ 2,000$ of earnings in the last year. Fourth, it eliminated the 2-week waiting period for benefits. Last, it allowed for more flexibility in the time and replacement rate of benefits with two options that parents should choose from.

\subsection{Theoretical Perspectives on Paternity Leave and Parental Earnings}

Human capital theory and the theory of signaling and statistical discrimination provide theoretical perspectives on the relationships between use of parental leave and parental earnings (Albrecht, Edin, Sundström and Vroman 1999; Johansson 2010; Mandel and Semyonov 2014). First, human capital theory views workers' wage as increasing with their human capital. This theory predicts that any time out of work would decrease labor market experience, leading to the depreciation of human capital and thus a reduction in wages (Mincer 1974; Mincer and Ofek 1982; Becker 1994). Secondly, the theory of signaling and statistical discrimination sees a worker's productivity or commitment to work as private information, and that taking time out of the labor force for parental leave can signal weaker commitment to work to their employer (Spence 1973; Aigner and Cain 1977; Weiss 1995; Albrecht et al. 1999). Based on this signal, an employer may pay lower wages or choose not to promote those who use parental benefits. These two theories have been applied to explain lower wages for mothers who take time off work after giving birth (Kim and Polachek 1994; Albrecht et al. 1999; Phipps, Burton and Lethbridge 2001), and are also relevant for predicting the consequences of fathers' use of paternity leave on fathers' earnings. Both theories predict that fathers' use of parental benefits will reduce fathers' earnings in the future.

Human capital theory and signaling theory also provide theoretical perspectives on the effect of fathers' use of parental benefits on his female partner's earnings. First, a combination of division of labor within household and human capital theory make a prediction on the effect. Becker (1973) argues that the family benefits from specialization. That is, the partner that has a comparative advantage in childrearing should specialize in child care and the partner that has the 
comparative advantage on the labor market should specialize in market work. If a father uses paternity leave, and gains childcare and home skills, then the couple's degree of specialization will be reduced. In particular, the female partner's comparative advantage in the labor market will increase. If it is the case, the woman may spend more time in the labor market and accumulate more human capital. This predicts that fathers' use of parental benefits will increase mothers' earnings in the future. Second, signaling and statistical discrimination theory also makes a positive prediction for the effect of father's use of paternity benefits on his partner's earnings. As it becomes more common for male coworkers to take time off work to care for children, the use of paternity leave becomes a noisier signal which is less informative for knowing the workers' commitment to work. As a result, when more men use paternity leave, this

will reduce statistical discrimination against female workers. In addition, father's use of paternity leave may signal to his partner's employer her stronger commitment to work by implying that she is not the sole caregiver at home.

Our prediction about the effect of paternity leave on family income is inconclusive because the net effect depends on the impact on the partners' incomes and relative sizes of both the impacts. If the negative impact of paternity leave on father's income dominates the positive impact on mother's income, family earnings are predicted to decrease. If the positive impact on mother's income outsizes the negative impact on father's income, then family earnings will increase. Lastly, if the impact on father's and mother's income have a similar magnitude, then family income would be unaffected by father's use of paternity leave. An empirical analysis is required to find out whether the effect of father's use of paternity leave was consistent with the theoretical predictions and to figure out the sign and size of the net effect on family income.

\section{Empirical Framework}

\subsection{Methodology}

We examine the effects of new fathers' use of parental benefits on their earnings, their partners' earnings, total family income, and wage inequality within couples. We examine these effects starting in the short-run (2-3 years after a first birth), through to the long-run (up to ten years after a first birth). We estimate the local average treatment effect (LATE) by exploiting the introduction of extended leave for fathers in Quebec in 2006, which generates random variation in the propensity for fathers to use benefits, as an instrumental variable. This allows us to 
examine the causal effects of fathers' use of leave on earnings among compliers. In addition to an IV, we use individual fixed effects to estimate the impact of paternity leave to control for unobserved time-invariant characteristics. This accounts for time-invariant characteristics like education, which is unavailable in our data, as well as individuals' time-invariant preferences. We estimate our LATE estimates using a two-stage least squares (2SLS) model.

We estimate the effects of father's use of parental benefits on earnings with equation (1):

$$
Y_{i t}=\eta_{i}+\gamma \text { Takeup }_{i t}+\boldsymbol{X}_{i t} \boldsymbol{\beta}+u_{i t} .
$$

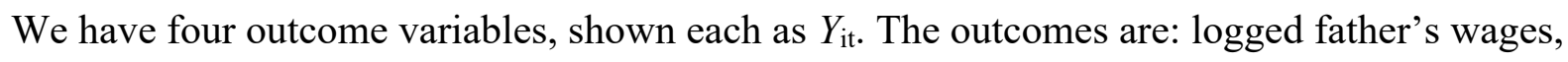
logged father's partner's wages, logged total family income, and relative wages within the couple. For each outcome, we estimate the effects on wages in each year separately from two years after a first birth to ten years after a first birth. Each model uses two years of data, the prebirth year and the $\tau$-th year after birth. On the right side of the equation, Takeup $p_{i t}$ is our independent variable of interest. We also include an individual fixed effect $\eta_{i}$ which removes any time-invariant source of variation, such as preferences or propensities to take leave that might be correlated with both earnings and the decision to use parental benefits. This equation also includes a set of control variables, $X_{i t}$, that include variable Post $_{i t}$, the square and cube of fathers' age, and dummies for the current province of residence such as the binary variable Quebec $_{i t}$, equal to one if the respondent lives in Quebec and zero otherwise, which captures any pre-reform differences between Quebec and other provinces in fathers use of leave. The variable Post $_{i t}$ is a dummy variable equal to one if the observation is in a post-birth year and zero otherwise, capturing any changes across time common to Quebec and other provinces.

There are good reasons to believe that fathers who use parental benefits may have different earnings or earnings trajectories than those who do not because their unobserved characteristics are different. To deal with this selection issue, we estimate a first stage model which uses the policy reform as a quasi-random experiment. This eliminates selection into the use of parental benefits. The equation for take-up is:

$$
\text { Takeup }_{i t}=\gamma_{1} \text { QPIP }_{i t}+\gamma_{2} \text { BirthQuebec }_{i t}+\gamma_{3} \text { Birth2006 }_{i t}+\boldsymbol{X}_{i t} \boldsymbol{\delta}+\epsilon_{i t} .
$$

The first stage model estimates whether fathers use parental benefits as a function of exposure to the QPIP policy. Variable BirthQuebec $c_{i t}$ is a dummy variable indicating if father $i$ has the first child in year $t$ and the child was born in the province of Quebec. Variable Birth2006 ${ }_{i t}$ is a dummy variable indicating if father $i$ has the first child in year $t$ and the child 
was born in year 2006. Variable $Q P I P_{i t}$ is an instrumental variable, which is equal to one if father $i$ has the first child in year $t$ and his first child was born in Quebec after 2006 and zero otherwise (when his first child is born in all other provinces, in Quebec before 2006, or one year before the first child was born). This equation also includes the same set of control variables $\boldsymbol{X}_{i t}$ as Equation (1). Lastly, $\epsilon_{i t}$ is an idiosyncratic error term, assumed to be independent of our instrumental variable QPIP. This assumption of the independence of the error term for this policy reform has been shown to hold by Patnaik (2019) in which she carefully shows that there was no self-selection in and out of the treatment group with systematic migration across provinces around the reform, other policy changes that may influenced our outcomes, nor strategic manipulation of births for the new benefit. She also shows that there are parallel trends in fathers' use of parental benefits between Quebec and the rest of Canada.

\subsection{Data}

To examine the use of parental benefits and parents' wages over time, we use longitudinal administrative data. The primary data source is the T1 Family File (T1FF), compiled by Statistics Canada from the primary tax return (the T1) which includes all individuals who filed an individual tax return, their filing and non-filing spouses/partners, and their children who reported the same address as their parent. The T1FF accounts for $96 \%$ of Canada's total population as of 2014 (Statistics Canada 2016). The coverage of newborns in the tax data is high, 96 to 98 percent of births measured in vital statistics, since the introduction of the Universal Child Care Benefit in 2005 (Hou et al. 2017). We combine the T1FF data across multiple tax years (2004-2016) at the individual level, using a unique person identifier. The linkage procedures involve identifying parents with a newborn child in the 2005 and 2006 in the T1FF, linking their information in the year right before the birth year and the years after. These data are ideal for the project since they include information on the timing of births, income from various sources over time (including parental benefits), marital status, and sociodemographic variables like sex, age, and immigrant status, and they are linked with data for partners/spouses. The data allow the analysis of wages for both partners over the course of the transition to parenthood up to ten years after a first birth, and the data set is large enough to examine heterogeneous effects for subpopulations.

Our analytic sample focuses on fathers who had their first child between January 2005 and December 2006, one year before and one year after the institution of QPIP in January 2006. 
Since a birth history of tax filers is unavailable, we define first time fathers as those who had no children living in their census family in the year before the focal child's birth. Because we are interested in the impacts of father's use of benefits on his own earnings as well as his partner's earnings, we restrict our sample to men who reported as married or living as common law in an opposite-sex couple in which both are aged between 18 and 45 in the birth year and have a valid spousal information. In our additional analysis, we restrict the sample to couples with both partners reported positive earnings one year before and $\tau$ years after the birth. To avoid the impact of divorce or separation on earnings in our estimates, our sample is restricted to those who remain married to the same spouse or "living as common law" (i.e. non-marital cohabitation) with the same partner in both observations. Most of these couples are married, but some of them are cohabiting. We refer to the members of these couples as partners throughout the paper, whether they are married or not. These restrictions leave us with an analytic sample of 100,867 fathers at five years after a first birth and 92,615 fathers at ten years after a first birth.

We have four dependent variables. The first two outcomes are logged father's and partner's earnings two to ten years after birth of the first child. The third is logged family income, measured as the sum of earnings of all census family members in a given year. We also estimate this separately from two to ten years after the birth of the first child. The fourth measures income inequality within the couple and is the female partner's share of family income. Our primary measure of income focuses primarily on paid employment income which includes wages, salaries and commissions (income reported T4 slips). In supplementary analysis, we also examine total income which includes income from paid employment, self-employment, investment income, and government transfers, but not capital gains. All monetary values are adjusted to 2015 Canadian dollars using annual Consumer Price Index at the national level.

As key independent variables, we use a dummy variable, denoted by Takeup ${ }_{i t}$, indicating whether a father used parental benefits for their first child or not. We define the use of parental benefits based on whether the parent received EI 'special' benefits or QPIP benefits in the first child's birth year or the following calendar year. Note that unemployment benefits belong to EI 'regular' benefits and maternity and parental benefits are part of EI 'special' benefits. Our instrumental variable captures exposure to the QPIP reform. The exposure to the QPIP is measured by a dummy variable, denoted by $Q P I P_{i t}$, indicating if the first child has been born in Quebec in 2006, and zero if the child was born in Quebec in 2005 or in another province. 
These dummy variables for father's take-up and exposure to the QPIP are set to zero at the prebirth year for all fathers. The square and cube of fathers' age are coded as the square of fathers' age divided by 1000 and the cube of fathers' age divided by 10000 .

Table 1 provides descriptive characteristics of the new fathers in the main analytic sample, by whether they were in Quebec or the rest of Canada, and those who had their first child before the reform in 2005 or after the reform in 2006. The use of parental benefits for firsttime fathers remained at 13 percent outside Quebec from 2005-2006. In the province of Quebec, the use of parental benefits was little more than twice the use in the rest of Canada, at 28 percent. It increased dramatically to 79 percent after the reform. The average age of the new fathers in our sample is 32 years old, and the fathers in Quebec are on average one year younger than those outside Quebec. The rest of the table shows our outcomes of interest at the year before and the $10^{\text {th }}$ year after the birth year: median income of the male partner, female partner, and family and average share of the female partner's contribution to family income. Parents in Quebec have lower income both at the individual level and at the family level, compared to those living in the rest of Canada. During the period of one year before and ten years after the birth year, the median income of male partners displays similar percentage increases across Canada around $72 \%$. Meanwhile, changes in the median income of female partners shows a stark difference between Quebec and the rest of Canada. During the same period, female partners living in Quebec shows growth in the median paid employment income by $59-61 \%$, whereas female partners living outside Quebec shows an increase by $38-41 \%$. It is common across Canada that the share of female partner's contribution to family income is similar before they became parents. While the share decreases after they became parents, it is higher in Quebec.

Table 2 displays descriptive characteristics of fathers who used parental benefits or not, and whether they were in Post-reform Quebec, Pre-reform Quebec, or the rest of Canada. The top of the table shows characteristics in the birth year and pre-birth year. In the province of Quebec, fathers who used parental benefits have higher median income than those who did not, but their median income did not grow as much as those who did not use parental benefits after ten years. The next section of Table 2 shows characteristics ten years after the focal birth. Mothers whose partner used parental benefits have higher income before the birth than those whose partner did not $(\$ 60,500$ vs. $\$ 52,500$ in Post-reform Quebec and $\$ 67,300$ vs. $\$ 58,900$ in the rest of Canada). Ten years after a birth, mothers whose partner used parental benefits and 
whose partner did not have very different patterns in their earnings growth. In the province of Quebec, the median paid employment income of non-takers' female partners increased by 55$56 \%$, whereas that of takers' female partners increased by $64-66 \%$. In the rest of Canada, the former experienced a growth of $38 \%$ while the latter experienced a growth of $53 \%$. Overall, men who used parental benefits and their partners contribute to family income more equally than nontakers and their female partners after the birth (43.0\% vs. $40.5 \%$ of female partner's share in family income in Post-reform Quebec and $42.8 \%$ vs.38.4\% in the rest of Canada).

The bottom of Table 2 shows how the characteristics of fathers vary in the year before the birth by three categorical variables that we use for our heterogeneous effect analyses: total family income quartile, relative income, and number of children in the $10^{\text {th }}$ year. In Canada outside of Quebec, the characteristics of fathers who use parental benefits and those who do not are mostly similar. However, in the province of Quebec, there are larger differences between fathers who use and do not use parental benefits, especially after the QPIP reform. In terms of absolute family income, fathers who did not use benefits are more likely to be from low-income families and less likely to be from middle-income families. Meanwhile, fathers who used benefits are less likely from the top income families. In terms of relative income before the birth, fathers who used parental benefits are more likely to have a partner contributing a similar share to family income. Fathers who took up parental benefits are more likely two or more children 10 years after the first child was born, compared to fathers who did not.

Our next descriptive table shows how labor force participation of couples changes after the birth. Table 3 shows the distribution of couples across employment status by time after the first birth. The first column shows that one year before the birth $81 \%$ of married couples whose first child was in 2005 and 2006 had two spouses with paid employment. The remaining columns show how these couples' employment status changed over time. Two years after the birth, $80 \%$ of the couples kept two spouses (dual earners) working at a paid job. The fraction of dual-earner couples then decreased to $74 \%$ five years after the birth and bounced back to $76 \%$ ten years after birth. Fathers in these couples are those in our final analytic sample. Meanwhile, the fraction of the couples with only the male partner having a paid job shows an inverse U-shape, starting from 15\% in the $2^{\text {nd }}$ year, peaked at $19 \%$ in the $5^{\text {th }}$ year, and decreasing to $16 \%$ in the $10^{\text {th }}$ year. Among those who were in a dual-earner couple before the first child is born, the fraction of partners continuing working at a paid job two years after the birth was $83 \%$ for female partners and $95 \%$ for male 
partners. For men, this fraction gradually decreases to $92 \%$ in the $10^{\text {th }}$ year as they became nonemployed or self-employed over time. For women, the fraction decreases to $78.6 \%$ in the $5^{\text {th }}$ year and increase back to $82 \%$ in the $10^{\text {th }}$ year. All in all, after the first birth, one in five mothers in a dual-earning couple stops their paid work, whereas the other four in five mothers remain in paid employment.

\section{Effects of Fathers' Use of Parental Benefits on Wages}

\subsection{Main results}

Figure 1 presents the estimated effects of fathers' use of parental leave on his own earnings, those of his partner, and family income. The models are estimated for each year separately up to 10 years after the first birth. The blue dots examine the effects of father's use of parental benefits for his own wages from two to ten years after a first birth. We find that fathers' use of parental benefits has small negative effects on his own earnings. This negative effect is largest in the short run, 13.7 and 12.9 percent in years two and three after a first birth. Then, the negative effects get smaller, declining to $6.9 \%$ in year four, and then $4.3-4.6 \%$ in years five to seven and $5.4-5.5 \%$ in years eight to ten. Part of the largest short-term effects in the first few years may be due to being on leave from work with a second or third child. However, there are still negative effects, although smaller, ten years after a first birth.

Although the use of father's leave has a negative effect on his own wages, we see a very different finding for the effect on his partner's earnings. The red diamonds show that women have lower wages for years two to three when children are still young, and she may be on leave again with a second child. However, starting in year four, there is a large positive effect on her wages, $13.8 \%$ in year four and increasing to $28 \%$ in years eight to ten. The green crosses show that the small negative effects on men's wages and large positive effects on women's wages cancel each other out. At years two and four after the birth, family income is lower. However, at years five and six after the birth, family income is not affected, and starting in year seven, there are positive impacts of fathers' use of parental leave on family income, at $2.6 \%$ in year seven and increasing to $3.4 \%$ at year ten.

Another family-level outcome to examine is the relative contribution of each spouse to family income (Figure 2). We find that father's use of parental benefits increases his partner's 
share in family income. The effect becomes stronger over time from $1 \% \mathrm{p}$ in the $2^{\text {nd }}$ year to $3.5 \% \mathrm{p}$ in the $5^{\text {th }}$ year to $5.4 \% \mathrm{p}$ in the $10^{\text {th }}$ year after birth. This finding supports that fathers' use of parental benefits improves parity within family in terms of economic contribution and brings higher family income in the long run.

To show that our results do not depend on the measure of income, we estimate a series of supplementary analysis using other measures of income. First, we use logged employment income that includes income from self-employment as well as from paid employment because expanding the coverage of parental insurance to self-employed people was one of several changes of the QPIP reform in 2006. These results (shown in Appendix Figure A1) are almost the same as those in the main text in Figure 1. Second, we use logged total income that includes employment income, investment income, and government transfers, and results are shown in Figure A2 in Appendix. Because parental benefits and child benefits are included in total income, estimates for the effects of using paternity leave on partners' income are even larger than those presented in the main results, and these estimates range between $22-25 \%$ throughout years two to ten years after the first birth. Last, to test that our results are not affected by the sample restriction, we use a balanced sample of families where both partners had paid employment income for entire period of one year before through ten years after birth of their first child. These results are in Figure A3 in Appendix. They show that estimates for fathers are almost the same as in Figure 1 and for mothers' earnings, although the estimated effect sizes are about half the size in Figure 1, we still find large positive impact from four to ten years after the birth. For family income, there is no statistically significant positive effect in the long run, but there is also no evidence if a significant long-lasting negative effect on family income.

\subsection{Subgroup Analysis}

The last part of our analysis examines whether the impacts of using paternity leave on earnings are different for subgroups where couples are likely to have different earning dynamics or fertility behavior. We apply the same methods as described above to the same analytic sample, but stratified in three different ways. We examine family income quartiles, relative income 
within the couple, and family size. ${ }^{3}$ First stage coefficients and the distribution of families across subgroups are reported in Table 2A in the Appendix, and the second stage estimates are reported graphically in Figures 3 to 5.

First, families at different points of the income distribution may make different decisions about how to share work and family roles. There is recent evidence that low- and high-income families were affected differently by the policy reform in how they use and share leave (Margolis et al. 2019). Figure 3 examines how couples in each income quartile benefit from having fathers use paternity leave (Figure 3). The sample is categorized by family income in the calendar year before the first child's birth. For families in the top income quartile, the effects of using parental benefits affected income trajectories differently from other income quartiles. We find that in terms of family income, the top income quartile gained the most. Among these families, fathers' use of parental benefits barely affected their own earnings between years four and year ten. The positive impact for mothers' earnings gradually increases from year four to ten. As a result, overall family income was $7 \%$ higher in the $10^{\text {th }}$ year for the fathers who used parental benefits in the top quartile. Meanwhile, the bottom quartile results tell a different story. The impact of fathers' use of parental benefits is negative and larger than the higher income quartiles, and there is no income bump for their female partner until year seven. Although there is positive impact on their spouse's earnings between years eight and ten, overall family income is lower after the birth. Lastly, for the middle two quartiles, the results for the middle two quartiles are different from the top and bottom quartiles. Fathers in both middle quartiles saw lower wages because of use of benefits, but their partners have higher wages with a jump at year four in both groups. This leads to no significant increase or decrease in family income for the lower middle quartile (Q2) and a small increase in the family income for the upper middle quartile (Q3). Overall, negative impact on fathers' earnings is larger for the lower income group. In terms of mothers' earnings, those in the middle-income families saw the largest positive impact.

Second, we examine how the effects vary by the relative earnings within the couple because egalitarian and traditional couples likely have different modes of sharing work and

\footnotetext{
${ }^{3}$ In addition to these three groups, we analyzed subgroup analysis by age differences between spouses and by female partner's age. We did not find noteworthy heterogeneous effects across groups, so we do not report them in this paper.
} 
family responsibilities. Figure 4 shows the results for three groups sorted by relative income earned within the household in the year before the first child's birth. The main findings that we have about fathers' earnings declining slightly from using leave and earnings of their spouse and family increasing are seen clearly among couples that earn relatively equally, with each partner earning between 40 and $60 \%$ of family income. Among these couples, fathers who used parental benefits earn 6-8\% less between years five and ten after the first birth than fathers who did not. The positive effects on mothers' earnings gradually increase from $16 \%$ at year four to $29 \%$ at year ten. As these families account for about half of our sample, results for those are almost the same as our main findings. Among couples where fathers earn more than $60 \%$ or less than $40 \%$, estimates for family income are positive between years five and ten after the birth, but the couple sees no effect on family income overall. We do not find significant earnings reduction for fathers due to their use of parental benefits among male partners earning more than $60 \%$ of family income between years four and seven and among male partners earning less than $40 \%$ of family income between years four and ten.

Last, examining the effects by family size is important because realized fertility reflects preferences regarding work and family balance, and also because the number of births is important for interpreting the number of leaves that parents may be taking from the labor market. Figure 5 examines whether fathers' take-up matters differently for families by how many children they have in the $10^{\text {th }}$ year after the birth. Table A2 shows most couples live with two children ten years after the first child is born. We find stronger long-term positive impact of fathers' parental benefits on mothers' earnings as the couple have more children. At the $10^{\text {th }}$ year after the first birth, differences of spousal earnings between leave-taking and non-taking fathers are $10 \%, 27 \%$, and $44 \%$ for families with one child, two children, and three or more children. If we see the number of children as how many times a father uses paternity leave and helps his female partner stay in her career after childbirth, this finding implies that the positive impact of fathers' parental benefits on their female partners' earnings accumulates by the number of their take-up. We find a similar pattern for impact on family income. Estimated effects on family income increase from $-4 \%$ among families with one child to $4 \%$ and $7 \%$ among families with two and three or more children. Also, we find positive impact on mothers' earnings between years two to three after the first birth among families with one child, while finding negative impact among families with two children between years two to three. This finding supports that 
the negative impact for mothers during the early years in the main findings are due to having the second child. Meanwhile, there is small negative impact on fathers' earnings in the short run even among families with one child. It implies that our main finding of the short-term decrease in fathers' earnings is not entirely due to having the second child and there is a reduction in fathers' earnings due to their use of parental benefits.

\section{Discussion and Conclusion}

Gender wage gaps are still present despite profound transformation in the roles of men and women in the last century (Goldin 2014) with a declining gap in labor force participation and wages through the 1990s, after which there has been a stalling of the gender revolution (England 2010). Much research shows that the remaining gender wage gap is largely due to parenthood (Bertrand, Goldin \& Katz 2010; Angelov, Johansson \& Lindahl 2016; Kleven, Landais \& Søgaard 2018). This is consistent with the finding in Goldin (2014) who finds the largest gender wage gap around the time when couples have small children. In countries that offer paid parental leave to workers around the time of a birth, it is most often the mothers who use most of parental leaves at the onset of parenthood (Ray et al. 2009). To promote gender equality, some countries have introduced paternity leave reserved for fathers. Canada is one of the countries. The province of Quebec introduced 5-week paternity leave in 2006 and the rest of Canada has had access to it since March 17, 2019. There has been a substantial rise in fathers' use of paternity leave after the introduction of paternity leave in Quebec (Margolis et al. 2019). This policy has been shown to have lasting positive impacts on fathers' time spent in domestic work and mothers' time spent at work after parental leave ends (Patnaik 2019) and decrease union dissolution (Margolis, Choi, Holm 2019), but had limited impact of child development or health (Haeck, Paré, Lefebvre and Merrigan 2019).

In this paper, we focus on the economic consequences of fathers' use of paternity leave. In particular, we examine effects of father's use of parental leave on earnings of fathers, their female partners, and family over a 10-year period after birth of the first child. Although earlier studies find mixed results for these effects, we find clear evidence that fathers' use of paternity leave had large effects on parental earnings especially in the longer run. Family income in the longer run is an important outcome for families to think about as they make their decisions about how to share work and family responsibilities after the transition into parenthood. 
First of all, we find a small negative effect of fathers' use of paternity leave on their earnings in the both short and long runs, with the largest impact in the short run (-13.7\% in year 2 ) and smaller impact in the long run (-4.3\% in year 5 and $-5.5 \%$ in year 10$)$. The long-term negative effects may be due to either lower hours of work or lower wage rates per hour, and our data do not allow us to distinguish between these two. If fathers who used parental benefits spend less time at paid work than those who did not take leave, then the lower earnings can be explained without considering changes in wage rates. However, Patnaik (2019) finds that there is no statistically significant effect on fathers' time in paid work and usual weekly hours at work. If this is the case, the negative effects on fathers' earnings are likely to come from lower wage rates for fathers taking leave compared to fathers that to not take leave. Wage losses due to use of paternity leave are consistent with the prediction of human capital theory and signaling theory discussed in an earlier section. First, a decrease in earnings may be due to the loss of human capital during paternity leave. However, when we consider that fathers use on average five weeks of paternity leave under the QPIP, the long-term negative effect may be too large to be accounted for entirely by the five weeks of absence from work. As suggested in Albrecht et al. (1999), signaling may be an alternative mechanism. A decrease in earnings is due to signaling of weaker commitment to work and statistical discrimination against fathers who are absent from work for paternity leave. As in Albrecht et al. (1999), our results are not sufficient to distinguish between the two interpretations.

Second, we find that father's use of parental benefits had a large positive effect on their partner's income and that the positive effect has an upward trajectory. Five years after the birth, all other things being equal, mothers whose partner used parental benefits earn $18 \%$ more than those whose partner did not. The earnings gap becomes larger over time and reaches $28 \%$ ten years after the birth. The positive effect may be explained by Patnaik (2019)'s finding that mothers' time spent at paid work increased due to the QPIP reform. Also, it is consistent with the prediction made by a combination of division of labor within household and human capital theory and by theory of signaling. In addition, our main results show that the net effect on family income is positive.

After the QPIP reform, a large positive effect of fathers' use of paternity leave on mothers' income dominated a small negative effect on fathers' income from 7 to 10 years after the first birth. These findings confirm that fathers' taking paternity leave reduces gender equality 
in the labor market without lowering family income. Although earlier studies examine the effects of a paternity policy reform on fathers' and mothers' earnings separately, our analysis examines whether father's use of paternity leave on his partner's earnings reform by using the data where two spouses are linked and followed together over time. This finding is new in the literature.

A major contribution of our analysis is the fact that we examine the effects of paternity leave on parental earnings through a ten-year period after the transition to parenthood. We find that the effects on wages evolve over time. In particular, having their partner use parental benefits increases mothers' wages consistently from four years to ten years after the first birth. The small negative effects on fathers' wages are greatest during the first two to three years after the birth and then decreases. Part of dynamics during the first two to three years after the birth is that many families have a second child. Negative impacts are largest in the first few years after having a first child when couples are often planning or having another child. This is important for putting other findings into context. All earlier studies either look at short-term effects only or focus on the effect in a given year after the first birth (Johansson 2010; Cools et al. 2015; Avdic and Karimi 2018; Andersen 2018; Farré and González 2019). In contrast, our study shows timeby-time effects for a 10-year period, and this allow us to shed light on the evolution of the effects from the short run to the long run. We show that it is important for further research to examine mechanisms explaining how wage effects evolve over time.

Our study has some limitations. First, because of our interest in the transition to parenthood, we limited our analysis to first time parents. The effects of the reform or use of paternity leave may depend on how leave is shared for older children, but we did not examine that here. Second, in thinking about how the recent (2019) federal in Canada introducing paternity leave may affect earnings, we note that there are some differences between the Quebec reform (2006) and the recent federal reform. In particular, Quebec's reform increased earnings replacement, but the federal reform did not. Last, we cannot distinguish whether the negative effects of father's use of leave on his earnings is due to a decrease in human capital or signalling. Future research should try to distinguish between the mechanisms.

Despite limitations, this paper provides the most comprehensive analysis of earnings dynamics within a couple over the long-run over the transition to parenthood. By examining how the effects of paternity leave play out differently for men's own earnings and those of their partners, we are able to show how parents' relative earnings within a couple evolve over time 
and how the policy reform increases gender equality within the couple. These findings are important because they highlight that a policy designed to shift care and work responsibilities within couples did in fact lead to more equal wages within couples while also increasing overall family income over a 10-year period. An implication of these findings is that paternity benefits which encourage men to spend time at home with children will have positive impacts on gender equality in labor market overall. 


\section{References}

Aigner, Dennis and Glen Cain. 1977. Statistical Theories of Discrimination in Labor Markets. Industrial and Labor Relations Review, 30(2), 175-187.

Albrecht, James, Per-Anders Edin, Marianne Sundström, and Susan B. Vroman. 1999. Career Interruptions and Subsequent Earnings: A Re-examination Using Swedish Data. The Journal of Human Resources, 34(2), 294-311.

Andersen, Signe Hald. 2018. Paternity Leave and the Motherhood Penalty: New Causal Evidence. Journal of Marriage and Family, 80(5), 1125-1143.

Angelov, Nikolay, Per Johansson, and Erica Lindahl. 2016. Parenthood and the Gender Gap in Pay. Journal of Labor Economics, 34(3), 545- 579.

Avdic, Daniel, and Karimi Arizo. 2018. Modern Family? Paternity Leave and Marital Stability, American Economic Journal: Applied Economics, 10(4), 283-307.

Becker, Gary. 1973. A theory of the marriage: Part I, Journal of Political Economy, 81(4), 813845.

Becker, Gary. 1994. Human Capital: A Theoretical and Empirical Analysis, with Special Reference to Education (3rd ed.). University of Chicago Press.

Bertrand, Marianne, Claudia Goldin, and Lawrence F. Katz. 2010. Dynamics of the gender gap for young professionals in the financial and corporate sectors. American Economic Journal: Applied Economics, 2(3), 228-255.

Cools, Sara, Jon H. Fiva, and Lars J. Kirkebøen. 2015. Causal effects of paternity leave on children and parents. The Scandinavian Journal of Economics, 117(3), 801-828.

Dahl, Gordon B., Katrine V. Løken, and Magne Mogstad. 2014. Peer Effects in Program Participation. American Economic Review, 104(7), 2049-2074.

Ekberg, John, Rickard Eriksson, and Guido Friebel. 2013. Parental leave-A policy evaluation of the Swedish "Daddy-Month" reform. Journal of Public Economics, 97, 131-143.

England, Paula. 2010. The Gender Revolution: Uneven and Stalled. Gender \& Society, 24(2), 149-166

Farré, Lídia, and Libertad González. 2019. Does paternity leave reduce fertility? Journal of Public Economics, 172, 52-66.

Goldin, Claudia. 2014. A Grand Gender Convergence: Its Last Chapter. American Economic Review. 104(4), 1091-1119 
Haeck, Catherine, Samuel Paré, Pierre Lefebvre. and Philip Merrigan. 2019. Paid Parental Leave: Leaner Might Be Better. Canadian Public Policy, 45(2), 1-27.

Hou, Feng, Rachel Margolis, and Michael Haan. 2017. Estimating Parental Leave in Canada Using Administrative Data. Statistics Canada= Statistique Canada.

Human Resources and Skills Development Canada. 2005. Summative Evaluation of EI Parental Benefits. Final Report.

Johansson, Elly-Ann. 2010. The effect of own and spousal parental leave on earnings. IFAU WP 2010:4.

Kim, Moon-Kak, and Solomon W. Polachek. 1994. Panel Estimates of Male-Female Earnings Functions. The Journal of Human Resources, 29(2), 406-428.

Kleven, Henrik, Camille Landais, and Jakob E. Søgaard. 2018. Children and Gender Inequality: Evidence from Denmark. National Bureau of Economic Research (No. w24219)

Kotsadam, Andreas, Elisabeth Ugreninov, and Henning Finseraas. 2011. The long term effect of own and spousal parental leave on mothers' earnings. In Kotsadam, A. (Ed.) Gender, work \& attitudes. Ph.D thesis, University of Gothenburg. Available at http://hdl.handle.net/2077/25323

Mandel, Hadas and Moshe Semyonov (2014). Gender pay gap and employment sector: Sources of earnings disparities in the United States, 1970-2010. Demography, 51(5), 1597-1618.

Margolis, Rachel, Feng Hou, Michael Haan, and Anders Holm. 2019. Use of Parental Benefits by Family Income in Canada: Two Policy Changes. Journal of Marriage and Family, 81(2), 450-467.

Margolis, Rachel, Youjin Choi, and Anders Holm. 2019. The Unintended Effect of Paternity Leave on Union Stability: Evidence from the Quebec Parental Insurance Program. SocArXiv. July 25. doi:10.31235/osf.io/kqfd7.

Marshall, Katherine. 1999. Employment after childbirth. Perspectives on Labour and Income, 11(3), 18-25.

Marshall, Katherine. 2008. Fathers' use of paid parental leave. Perspectives on Labour and Income, 20(3), 5-14.

Mincer, Jacob. 1974. Schooling, experience, and earnings. New York: Columbia University Press.

Mincer, Jacob, and Haim Ofek. 1982 Interrupted Work Careers: Depreciation and Restoration of Human Capital. The Journal of Human Resources. 17(1), 3-24. 
Patnaik, Ankita. 2019. Reserving Time for Daddy: The Consequences of Fathers' Quotas. Journal of Labor Economics, Forthcoming. Available at SSRN:

https://ssrn.com/abstract=3225239

Phipps, Shelley, Peter Burton, and Lynn Lethbridge. 2001. In and out of the Labour Market: Long-Term Income Consequences of Child-Related Interruptions to Women's Paid Work. The Canadian Journal of Economics, 34(2), 411-429.

Ray, Rebecca, Janet C. Gornik, and John Schmitt. 2009. Parental Leve Policies in 21 Countries: Assessing Generosity and Gender Equality. Revised version. Center for Economic and Policy Research.

Rege, Mari, and Ingeborg F. Solli. 2013. The Impact of Paternity Leave on Fathers' Future Earnings, Demography, 50(6), 2255-2277

Spence, Michael. 1973. Job Market Signaling. Quarterly Journal of Economics. 87(3), 355-374

Statistics Canada. 2016. Annual income estimates for census families and individuals (T1 Family45 File): Family data: user's guide. Ottawa: Statistics Canada. Retrieved from http://www23.statcan.gc.ca/imdb-bmdi/document/4105_D5_T1_V13-eng.pdf

Weiss, Andrew. 1995. "Human Capital vs. Signaling Explanations of Wages". The Journal of Economic Perspectives. 9 (4), 133-154. 
Table 1. Descriptive Statistics

\begin{tabular}{lccccc}
\hline & \multicolumn{2}{c}{ Quebec } & & Rest of Canada & Total \\
& 2005 & 2006 & 2005 & 2006 & \\
& Births & Births & Births & Births & \\
\cline { 2 - 6 } & & & & & \\
Characteristics in the birth year & 27.9 & 79.1 & 12.8 & 13 & 23.3 \\
\hline Use of parental benefits & 31.32 & 31.46 & 32.23 & 32.29 & 32.04 \\
Mean age of male partner & 29.22 & 29.29 & 30.3 & 30.34 & 30.05 \\
Mean age of female partner & & & & & \\
Characteristics in the pre-birth year & 46,500 & 46,600 & 55,200 & 55,600 & 52,800 \\
Median income of male partner & 36,400 & 36,400 & 42,100 & 43,700 & 40,900 \\
Median income of female partner & 83,600 & 84,000 & 98,700 & 101,400 & 95,200 \\
Median income of family & 43.8 & 44.1 & 43.4 & 43.8 & 43.7 \\
Female partner's share in family income & & & & & \\
Characteristics in the 10th year after birth & 79,600 & 80,000 & 96,200 & 94,900 & 91,000 \\
Median income of male partner & 58,000 & 58,700 & 59,400 & 60,100 & 59,400 \\
Median income of female partner & 140,400 & 140,900 & 160,600 & 159,100 & 154,400 \\
Median income of family & 42.0 & 42.5 & 38.6 & 39.3 & 39.8 \\
Female partner's share in family income & 11,294 & 11,961 & 34,225 & 35,135 & 92,615 \\
\hline Number of Observations & &
\end{tabular}

Notes: Data are from Statistics Canada, the Historical T1 Family File. Our sample is restricted to parents whose first child is born between January 2005 and December 2006. The sample for the 10th year effects are used for this table. The measure of income in this table is income from paid employment. All money values are adjusted to 2015 Canadian dollars. Median incomes are rounded to $\$ 100$. 
Table 2. Descriptive Statistics: Fathers Who Used Parental Benefits Versus Those Who Did Not

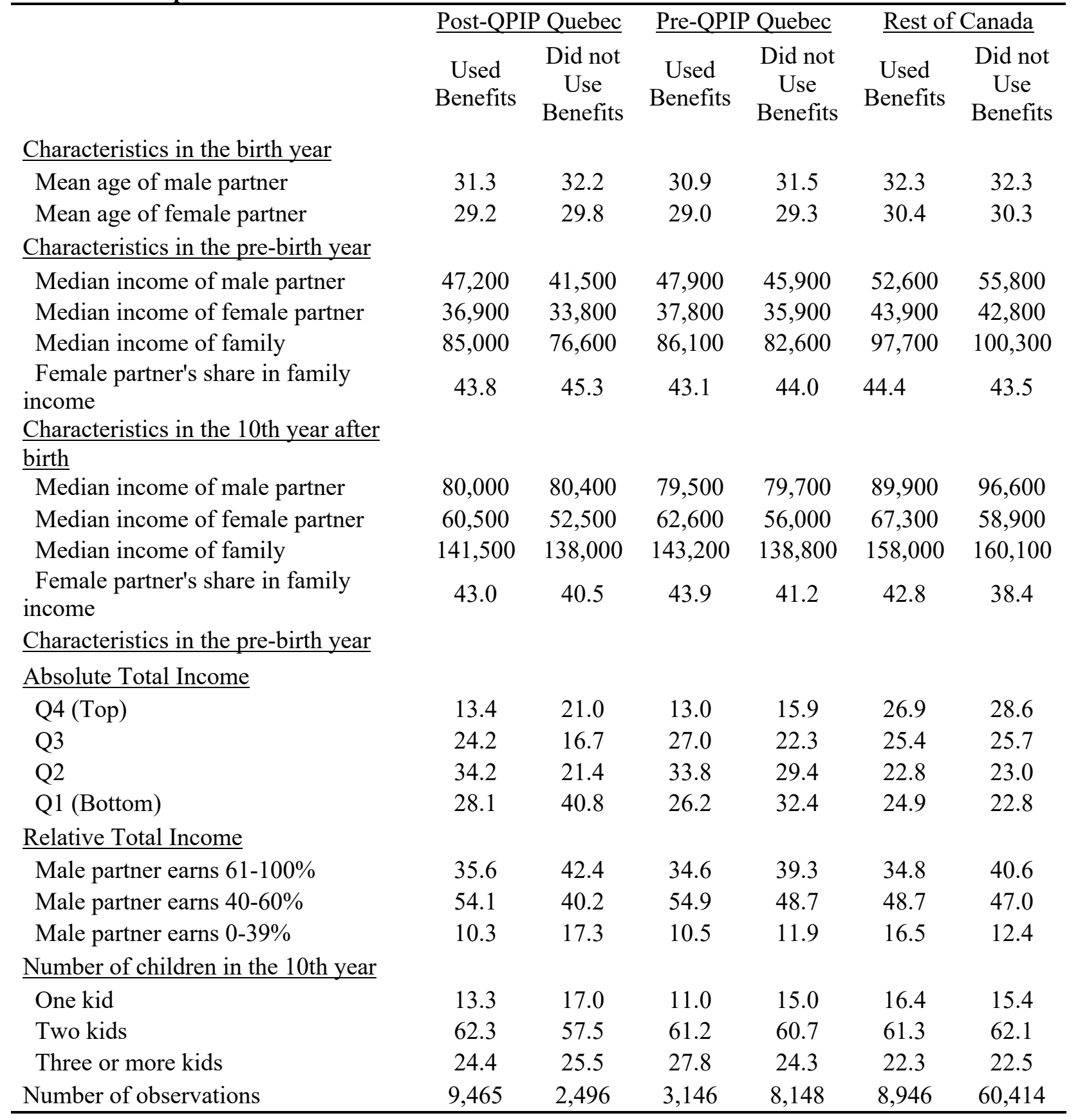

Notes: Data are from Statistics Canada, the Historical T1 Family File. Our sample is restricted to parents whose first child is born between January 2005 and December 2006. The sample for the 10th year effects are used for this table. The measure of income in this table is income from paid employment, whereas total income include income from all sources except capital gains. All money values are adjusted to 2015 Canadian dollars. Median incomes are rounded to $\$ 100$. 


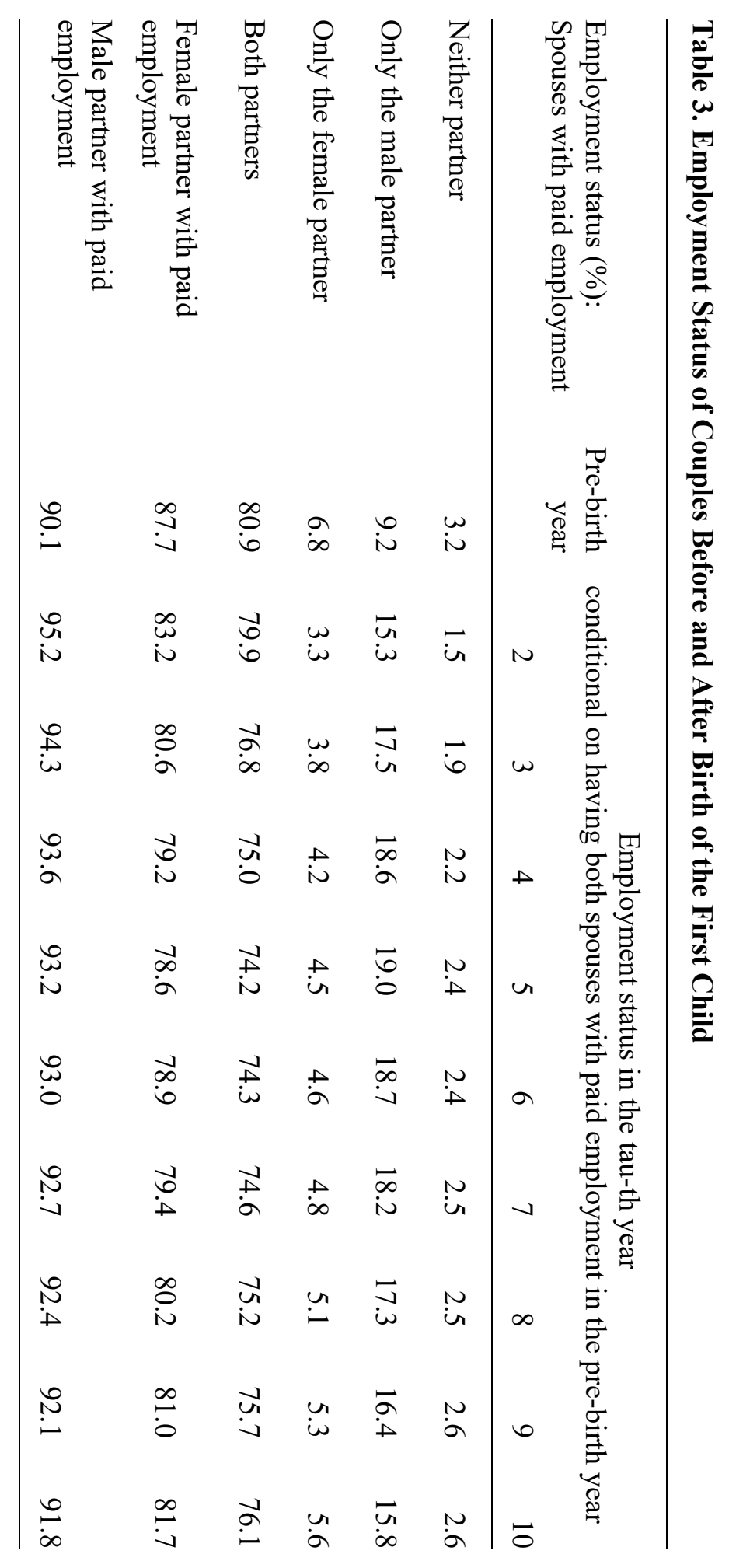




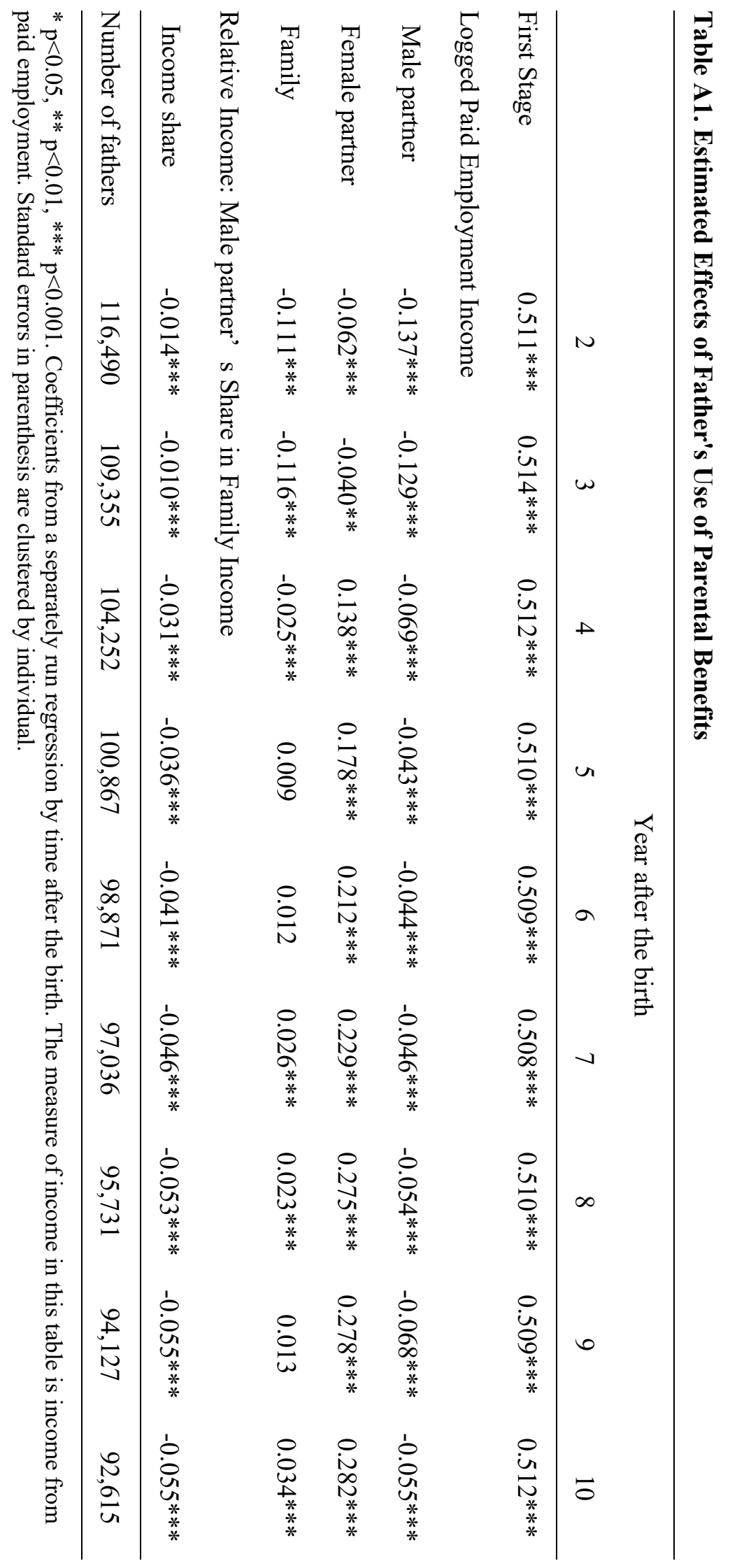


Table A2. First Stage Coefficients for Heterogeneous Effects

\begin{tabular}{llr}
\hline Subgroup & First stage & Distribution \\
\hline Pre-birth year family income quartile & & \\
Q4 (Top) & $0.461^{* * *}$ & 25.0 \\
Q3 & $0.526^{* * *}$ & 25.0 \\
Q2 & $0.552^{* * *}$ & 25.0 \\
Q1 (Bottom) & $0.487^{* * *}$ & 25.0 \\
Relative total income & & \\
Male partner earns 61-99\% & $0.511^{* * *}$ & 39.3 \\
Male partner earns 40-60\% & $0.527^{* * *}$ & 48.1 \\
Male partner earns 1-39\% & $0.441^{* * *}$ & 12.6 \\
Number of children 10 years after first birth & & \\
One child & $0.523^{* * *}$ & 15.1 \\
Two children & $0.521^{* * *}$ & 61.7 \\
Three or more children & $0.494^{* * *}$ & 23.1 \\
\hline
\end{tabular}

$* \mathrm{p}<0.05, * * \mathrm{p}<0.01, * * * \mathrm{p}<0.001$. This table is based on the analytical sample for 10 th year effects are used. 
Figure 1. Estimates by Time After the Birth: Fathers' Earnings, Mothers' Earnings, Family Income

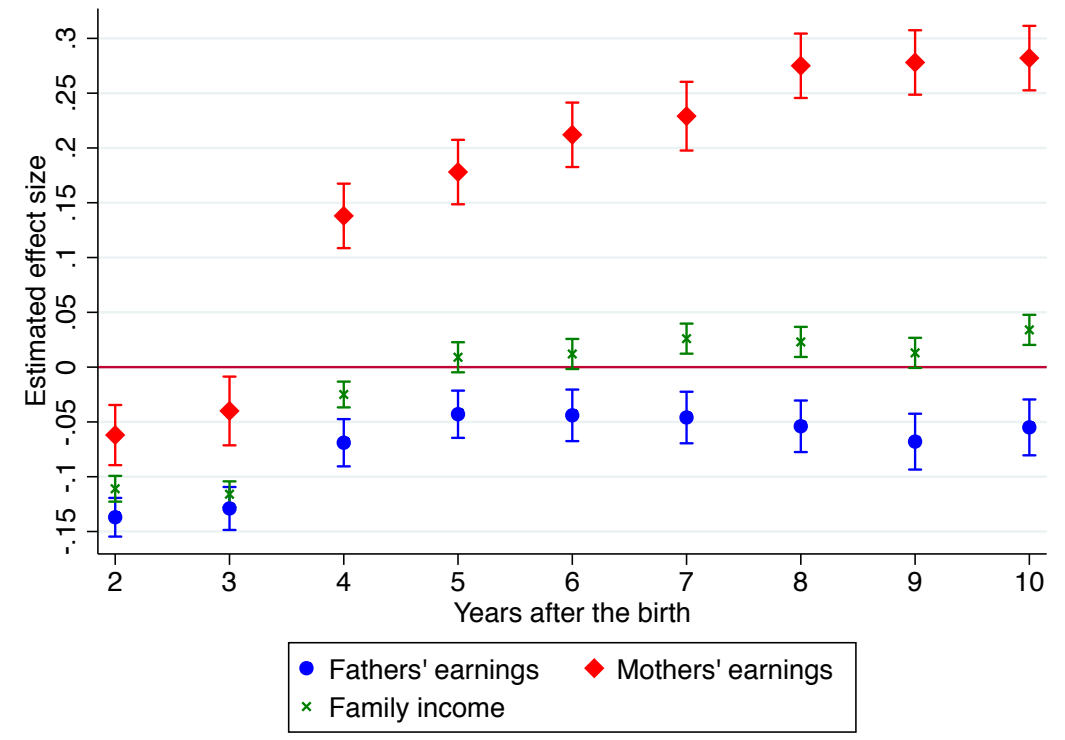

Note: Outcome variables are logged earnings from paid employment. Point estimates and $95 \%$ confidence intervals are from separate estimation by time after the birth. Standard errors are clustered by individual.

Figure 2. Estimates by Time After the Birth: Mothers' Share in Family Income

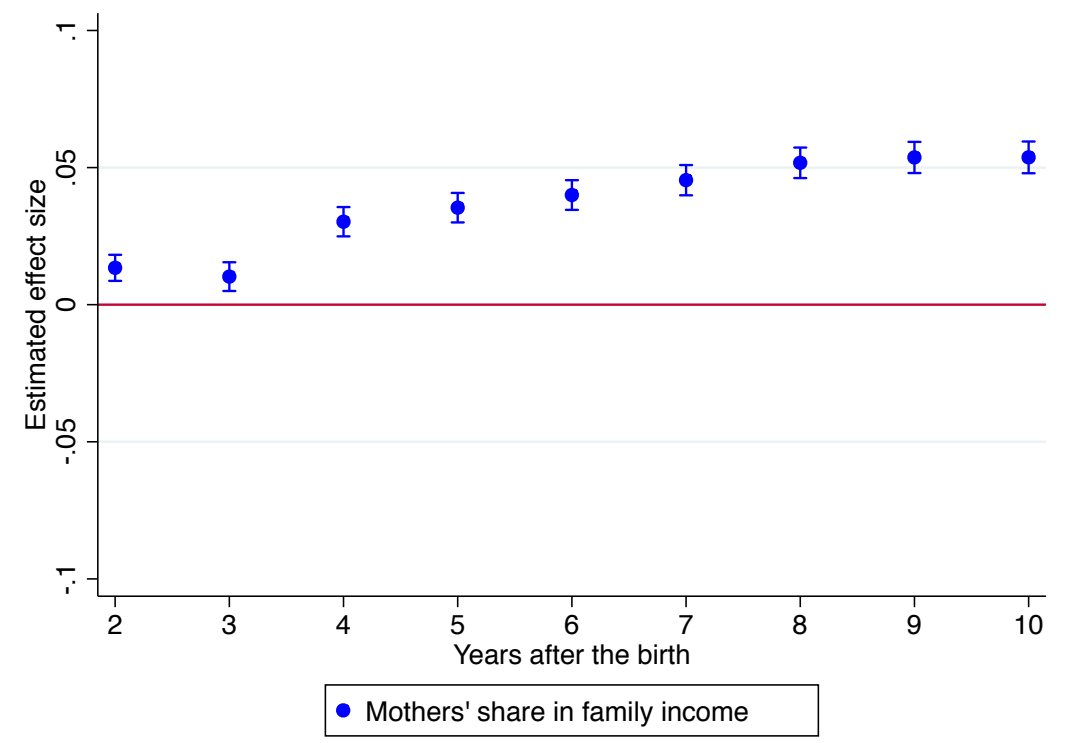

Note: Outcome variables are mothers' share in family income from paid employment. Point estimates and 95\% confidence intervals are from separate estimation by time after the birth. Standard errors are clustered by individual. 
Figure 3. Estimates by Pre-birth Family Income Quartile

(a) Q4 (Top)

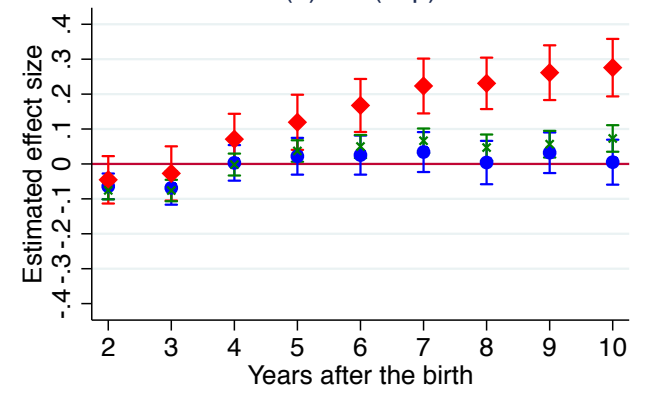

(c) Q2

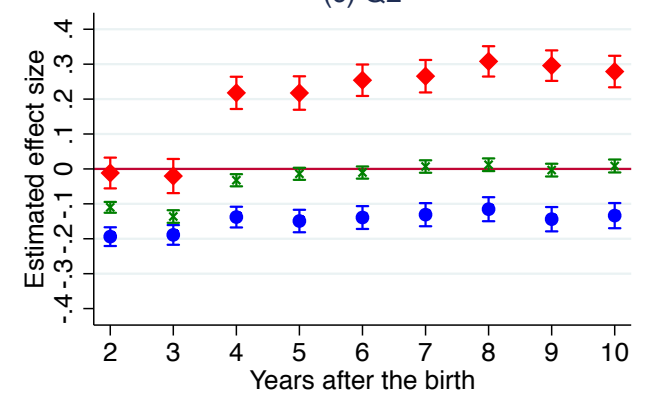

(b) Q3

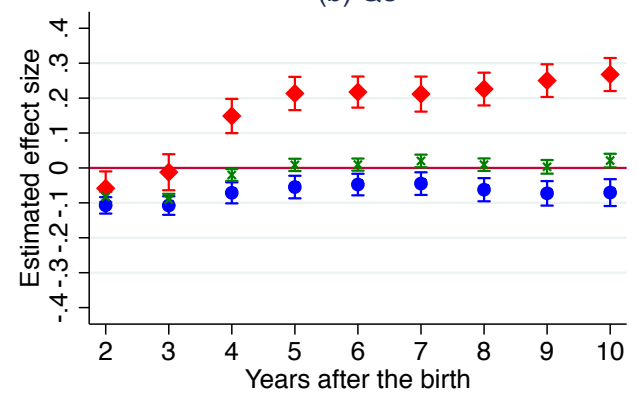

(d) Q1 (Bottom)

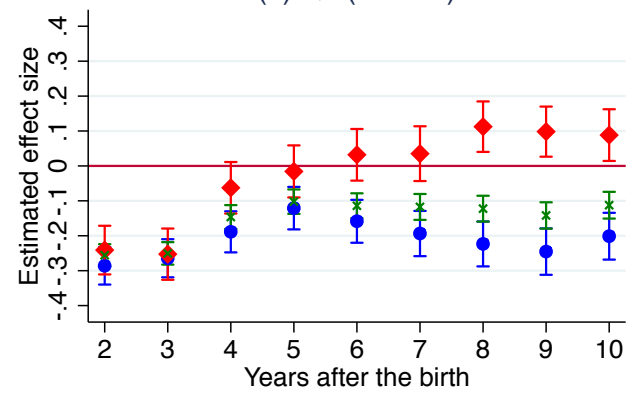

Note: Outcome variables are earnings from paid employment for fathers (blue dot), mothers (red diamond) and family (green cross). Family income quartiles are the quartiles of family total income, including income from paid employment and self-employment, investment income, and government transfers, one year before the focal child's birth. Coefficients are from a separately run regression by each subgroup. Standard errors are clustered by individual. 
Figure 4. Estimates by Relative Total Income

(a) Husband earns $61-99 \%$

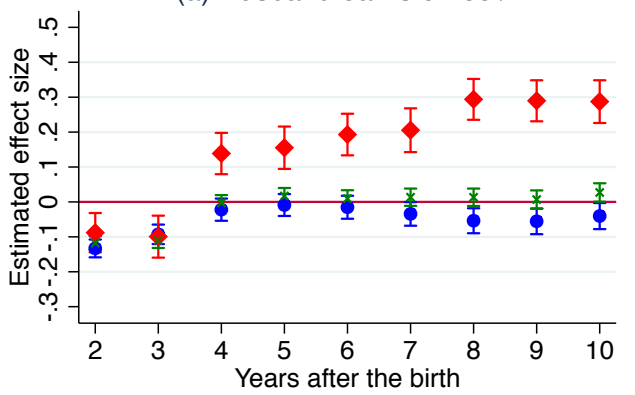

(c) Husband earns 1-39\%

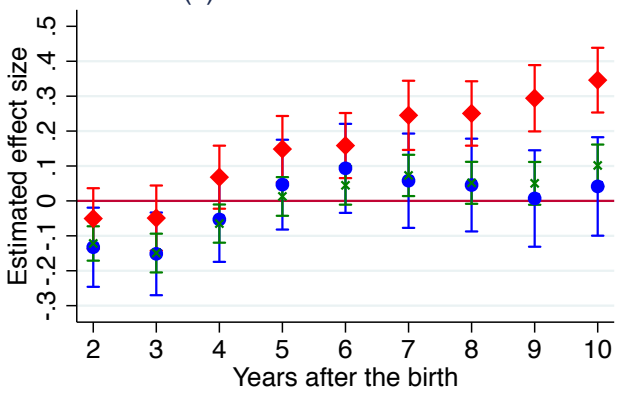

(b) Husband earns $40-60 \%$

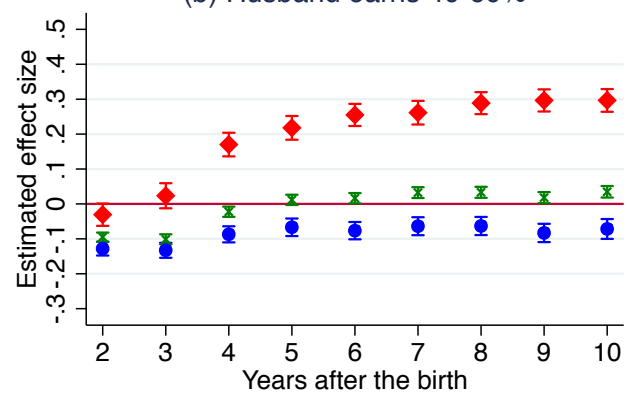

Note: Outcome variables are earnings from paid employment for fathers (blue dot), mothers (red diamond) and family (green cross). This subgroup is based on male partner's share in family total income one year before the focal child's birth. Coefficients are from a separately run regression by each subgroup. Standard errors are clustered by individual. 


\section{Figure 5. Estimates by Number of Children 10 Years After Focal Birth}

(a) One child

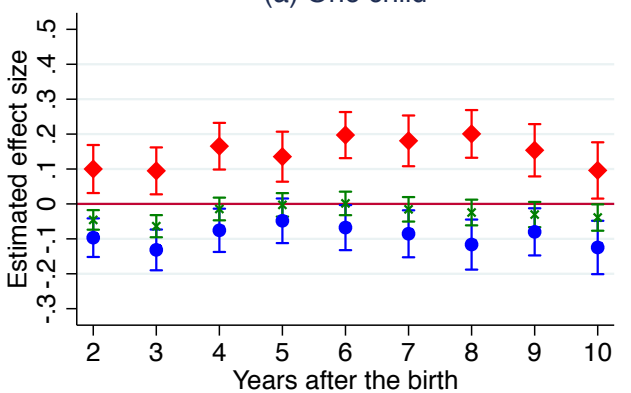

(c) Three or more children

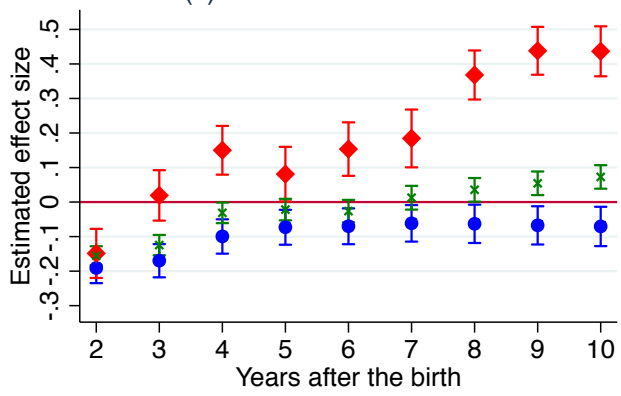

(b) Two children

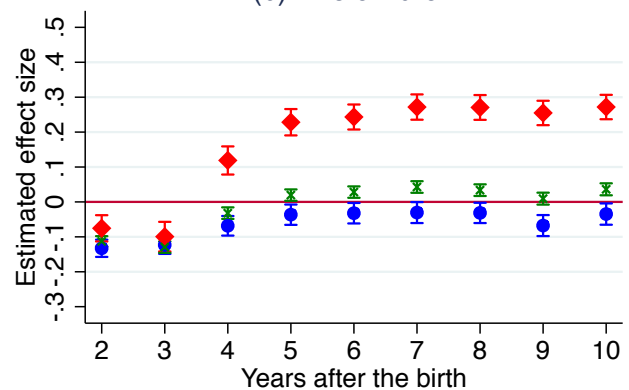

Note: Outcome variables are earnings from paid employment for fathers (blue dot), mothers (red diamond) and family (green cross). This subgroup is based on the number of children living in the census family 10 years after birth of the first child. The analytic sample for this analysis is limited to those who are observed in $10^{\text {th }}$ year. Coefficients are from a separately run regression by each subgroup. Standard errors are clustered by individual. 
Figure A1. Sensitivity Analyses - Logged Employment Income as Outcome Variable

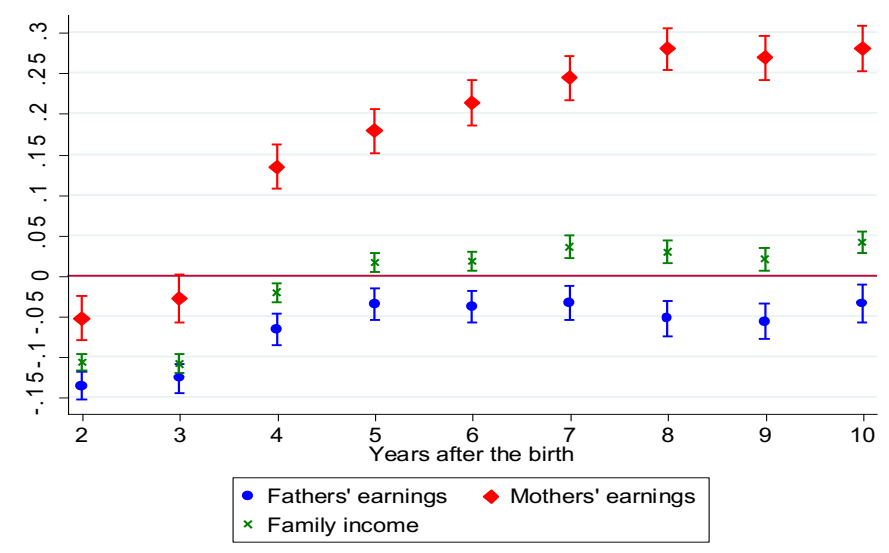

Figure A2. Sensitivity Analyses - Logged Total Income as Outcome Variable

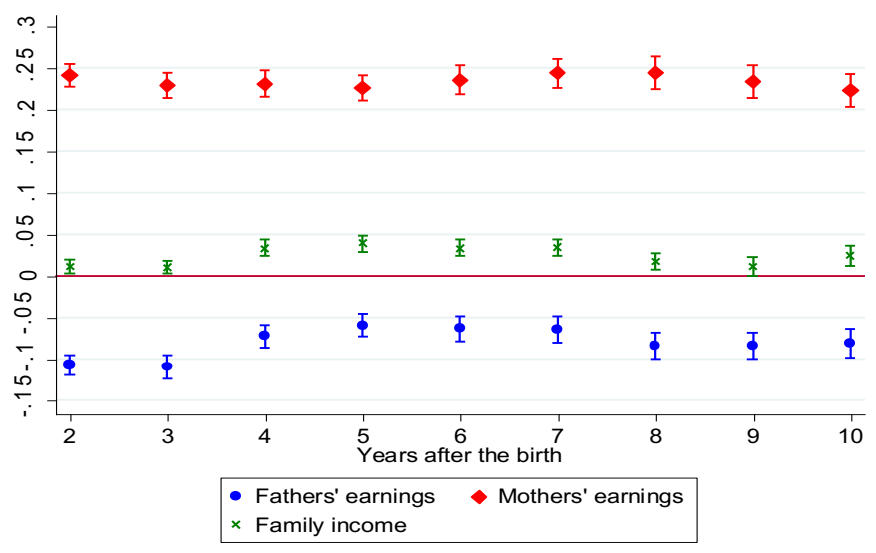

Figure A3. Sensitivity Analyses - Balanced Sample

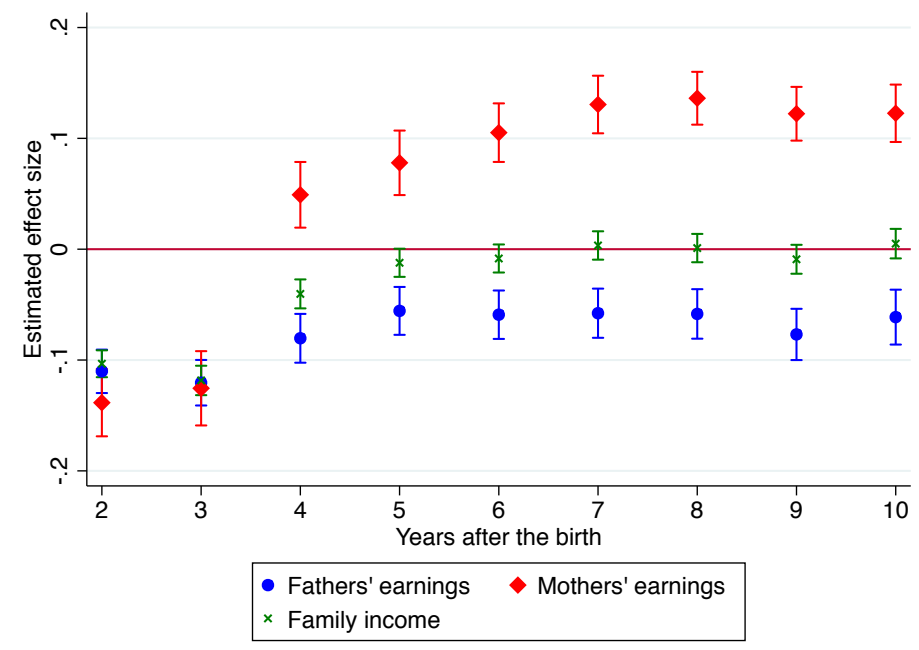

